\title{
RACISMO NO BRASIL: TENTATIVAS DE DISFARCE DE UMA VIOLÊNCIA EXPLÍCITA
}

\author{
Sylvia da Silveira Nunes ${ }^{1}$ \\ Faculdade Taboão da Serra - SP
}

\begin{abstract}
A escravidão negra no Brasil trouxe profundas marcas para a sociedade contemporânea. A ambigüidade presente no pós-abolição - ao negro não é negado o direito de ser livre, mas lhe são negadas condições dignas de vida, repetindo-se, muitas vezes, lógicas semelhantes a da escravidão -, de alguma forma, persiste nos dias de hoje por meio de práticas racistas, sejam elas explícitas ou não. No presente artigo, são analisadas as origens do racismo brasileiro por meio de reflexões sobre as relações raciais após o fim da escravidão. O foco da análise é o discurso científico legitimado pela importação de teorias raciais européias no início do século XX e sua particular apropriação pelos intelectuais brasileiros, especificamente, pela análise de uma obra do médico baiano Raimundo Nina Rodrigues. $O$ racismo justificado pela ciência foi a forma de manter a desigualdade de tratamento entre brancos e negros, nesse momento histórico. Essa desigualdade ainda pode ser observada nos dias de hoje. Para tal, são discutidas as formas de expressão do racismo atual.
\end{abstract}

Descritores: Preconceito. Relações étnicas e raciais. Problemas sociais.

... E queremos também que se reflita sobre a ambigüidade desta história de que são vítimas os negros, numa sociedade que os exclui de seus benefícios, mas consome os deuses, as comidas, a música e todas as festas de negros, esquecidos de suas origens. Por

1 Especialista em Psicologia do Desenvolvimento e Deficiência pela Universidade Estadual de Campinas, Mestre e Doutoranda em Psicologia Escolar e do Desenvolvimento Humano pelo Instituto de Psicologia - USP. Docente da Faculdade Taboão da Serra. Endereço para correspondência: Av. Prof. Mello de Moraes, 1235, Bloco C Apto. 401, Butantã, CEP 05508-030, São Paulo, SP. Endereço eletrônico: sylviasnunes@yahoo.com.br 


\section{Sylvia da Silveira Nunes}

isso, esta história não registra apenas o fracasso do negro frente às inúmeras injustiças sofridas, mas também sua vitória, no rastro profundo deixado na cultura brasileira por negros e mestiços, construtores silenciosos de nossa identidade. Tudo isso é memória, parte de uma história escamoteada que já não poderá mais ficar esquecida pela história oficial.

Emanoel Araújo, como curador da exposição

“Negras Memórias, Memórias dos Negros - O Imaginário Luso-Afro-Brasileiro e a Herança da Escravidão”, 2003.

$\mathrm{O}$

Brasil foi o último país a abolir a escravidão. Esse fato histórico, aparentemente longínquo, deixou, na verdade, profundas marcas na sociedade brasileira. Para entendê-las, é preciso não esquecer os navios negreiros e os objetos de tortura. É preciso lembrar que a abolição foi lenta. Mas é preciso também pensar o lugar que a ciência ocupou na consolidação do preconceito contra os negros. Para que se lute contra o racismo é preciso primeiramente reconhecer que ele existe. Sem essa "confissão" tira-se do foco $\mathrm{o}$ alvo que se quer atingir.

A partir de meados do século XVI e, oficialmente, até 1850 - data da lei que aboliu o tráfico de escravos negros -, chegaram ao Brasil milhões de pessoas vindas de diferentes partes do continente africano. Nesse período, a forma de relação com o escravo é muito clara, pois ele é visto como "peça", tratado como coisa que tem um proprietário: é alugado, vendido, comprado, entra na contabilidade das fazendas ao lado das cabeças de gado, das ferramentas e outros bens materiais.

O panorama geral da escravidão no Brasil, recomposto por vários historiadores, mostra que o regime escravista não foi menos violento do que em outros países. Ao contrário, podemos perceber uma violência cotidiana, multiforme e naturalizada, que nos dá pistas para o entendimento do racismo brasileiro atual. 
A esperada cidadania após a abolição não aconteceu e, até hoje, é uma luta constante em uma sociedade em que a desigualdade racial é arraigada e as tentativas de apagar a memória da barbárie contra os escravos são permanentes, quer pela eliminação de documentos, quer pela disseminação do mito da democracia racial.

Pouco depois da Lei Áurea, e já na vigência do regime republicano, mais exatamente em 14 de dezembro de 1890, Ruy Barbosa, Ministro e Secretário de Estado dos Negócios da Fazenda e Presidente do Tribunal do Tesouro Nacional, queimou documentos oficiais que eram prova da escravidão, sob a justificativa de apagar da história do Brasil um período vergonhoso (ver Costa, 1996). No mesmo ano, o Hino à República diz: "Nós nem cremos que escravos outrora/ tenha havido em tão nobre país”. A este respeito, Costa (1996) afirma:

... o Estado apropria-se da História, controla e manipula o entendimento do processo histórico, confunde a noção de temporalidade e impinge o esquecimento. Garante, assim, a continuidade do mesmo sistema sob nova e atual roupagem: sem escravos e, logo depois, sem rei. Para dominar, há que se tornar senhor da memória e do esquecimento. (p. 84)

Mudaram as aparências, mas a essência das relações sociais não mudou. A atitude do Estado para a situação do negro "liberto" sempre foi omissa: a miséria material, a discriminação e a humilhação vividas pelos afrodescendentes são reduzidas à culpa deles mesmos, por meio de uma manobra ideológica que transforma o que é da esfera das relações de poder em algo natural, inerente à raça ${ }^{2} \mathrm{~A}$ ideologia republicana pedia um projeto de nação que, por sua vez, requeria que se repensasse o homem brasileiro. Coube aos cientistas da época fazer esta reflexão.

2 É importante ressaltar que algumas conquistas do Movimento Negro começam a aparecer, oficialmente amparadas pelo Estado, tais como a criação, em março de 2003, da Secretaria Especial de Políticas de Promoção da Igualdade Racial, diretamente vinculada à Presidência da República; as discussões de políticas de ações afirmativas na Reforma Universitária; etc. As repercussões dessas iniciativas começam a surgir, mas há, certamente, um longo caminho a trilhar. 


\section{Sylvia da Silveira Nunes}

Raimundo Nina Rodrigues, médico baiano renomado, estudioso do negro e da criminalidade e grande adepto das idéias do antropólogo criminal italiano Cesare Lombroso, foi representante importante das teorias raciais no Brasil. Lutou pela implantação da Medicina Legal nos currículos das Faculdades de Medicina e defendeu a criação de dois códigos penais brasileiros: um para os brancos e outro para os negros, pois pressupunha que as diferenças raciais levavam a diferenças comportamentais e morais tão grandes que não se podiam fazer as mesmas exigências para ambas as raças. Para ele, como para outros cientistas de sua época, a igualdade de direitos e deveres era uma ilusão.

Em Africanos no Brasil, publicado em 1935, destaco um capítulo: "Valor social das raças e povos negros que colonisaram o Brazil, e dos seus descendentes”. O objetivo é pensar a influência do negro na constituição do povo brasileiro, tendo em vista contribuir para a grande questão política daquele momento: a natureza desse povo e suas possibilidades de evolução.

Ao fazer esta discussão, ele contribuiu para a instituição da Antropologia no país, detendo-se no estudo dos povos africanos trazidos para o Brasil: os chamitas, os bantus e os sudanezes. Por considerá-los mais inteligentes e capazes de organização, ele defende a tese de que boa parte dos negros que chegaram ao país tinha razoável nível evolutivo. É assim que Rodrigues, nesse capítulo, consegue conciliar a questão da degeneração e inferioridade do negro - tão divulgada por diferentes autores e reafirmada por ele mesmo - com a possibilidade de pensar sem tanto pessimismo o futuro do país.

Para ele, a inferioridade social do negro é um fato incontestável: "De facto, não é a inferioridade social dos negros que está em discussão. Ninguém se lembrou ainda de contestá-la. E tanto importaria contestar a própria evidência” (Rodrigues, 1935, p. 388). Sua discussão da questão da inferioridade do negro gira em torno da capacidade de civilizar-se desta raça. O ideal de civilização é o de povos da Europa: será que o negro é capaz de civilizar-se como o europeu? Entre as duas versões dominantes - a que concebe a inferioridade como "transitória e remediável” e a que a vê como inerente à constituição orgânica e, por isso, não há como remediá-la -, Rodrigues toma 
o que interessa das duas, de modo a ver saídas para o país, sem negar a hierarquia entre as raças.

Diante de autores que justificam a inferioridade do negro pela "ossificação precoce das suturas craneanas” (Rodrigues, 1935, p. 389) e a tomam como causa da incapacidade dos negros de "assimilar a civilisação dos diversos povos com que estiveram em contacto" e tampouco de "crear cultura própria”, Rodrigues argumenta que a ossificação precoce não é causa da inferioridade, mas é conseqüência desta: “A ossificação será precoce mas não prematura, pois ocorre em tempo e em harmonia com o reduzido desenvolvimento mental de que os povos negros são dotados” (p. 389).

Em relação à impossibilidade de civilização do negro, Rodrigues (1935) afirma que a ciência ainda não tem elementos para respondê-la. No entanto, é categórico na crítica às concepções otimistas de desenvolvimento do negro:

A allegação de que por largo praso viveu a raça branca, a mais culta das secções do genero humano, em condições não menos precarias de atraso e barbaria; o facto de que muitos povos negros já andam bem proximos do que foram os brancos no limiar do periodo historico; mais ainda a crença de que os povos negros mais cultos repetem na Africa a phase da organisação politica medieval das modernas nações européas (Beranger Feraud), não justificam as esperanças de que os negros possam herdar a civilisação europea e, menos ainda, possam attingir a maioridade social no convivio dos povos cultos. (p. 390)

Rodrigues toma existência de níveis de desenvolvimento diferenciados entre os povos negros como prova de que são capazes de civilizar-se. No entanto, por ser muito morosa, o grau de civilização alcançado pelos negros não será o da raça branca. É assim que ele justifica a hierarquia entre raças e se opõe a argumentos igualitários: “A geral desaparição do índio em toda a América, a lenta e gradual sujeição dos povos negros á administração intelligente e exploradora dos povos brancos, tem sido a resposta pratica a essas divagações sentimentaes” (p. 391). Tanto a escravidão do negro quanto a diminuição dos povos indígenas são entendidas como sinais de inferioridade dessas duas raças.

O problema da mestiçagem e de suas conseqüências sobre o atraso do país também é objeto de sua atenção: “quanto de inferioridade lhe advem da 


\section{Sylvia da Silveira Nunes}

difficuldade de civilisar-se por parte da população negra que possue e se de todo fica essa inferioridade compensada pelo mestiçamento” (pp. 391-392).

Para falar da diferença de capacidade de evolução do negro e do branco, Rodrigues (1935) vale-se de autores favoráveis aos grupos negros. Para um deles, o povo negro é degenerado devido a influências desfavoráveis externas, sendo necessários séculos de desenvolvimento para superar a degeneração resultante. A conversão dos negros ao cristianismo não faria com que as características morais (que são transmitidas geneticamente) mudem, pois "o negro convertido rebaixa invariável e necessariamente a nova religião ao nível de sua própria cultura mental” (p. 394). A capacidade de evolução do negro, embora admitida, só ocorre de forma gradual: "pois só quando um passo avante está dado com segurança é que o caráter de raça tornase firme e capaz de sofrer novo impulso” (p. 394). Assim, não adianta tentar impor a civilização ao negro, porque é importante que ele passe por todas as fases de evolução a fim de que a raça sofra as transformações necessárias para chegar ao estágio de civilização do branco.

Para falar sobre o negro na América, Rodrigues (1935) recorre a autores que defendem a tese de que aqui o negro teve progressos pelo seu convívio com as raças superiores, embora continue sendo culturalmente inferior, situado no estágio infantil de humanidade e, por isso, "não se pode resolver a tratar de igual para igual com uma gente tão inferior a elles, do mesmo modo que o adulto não trata a creança de igual para igual, nem as classes superiores ás inferiores” (p. 396). Negros e crianças têm em comum “a leviandade, o capricho, a imprevidência, a volubilidade, a intelligencia ao mesmo tempo viva e limitada” (p. 395), concepção que teve forte influência sobre Rodrigues, principalmente em sua defesa de um código penal especial para os negros. Mas esse progresso será sempre limitado e inferior ao do branco, pois, segundo estudiosos citados por Rodrigues, o negro só poderia alcançar o branco se o branco perdesse a capacidade de evoluir, hipótese vista como impossível por eles. Por isso, enquanto o branco dá passos largos evolutivos, o negro só consegue dar pequenos passos quando em contato com os civilizados, o que faz com que o atraso em relação ao branco seja irreversível. Assim Rodrigues conclui sobre as vantagens da vinda dos negros para a América, “onde (...) 
estão collocados em condições de meio e cultura a todos os respeitos mais favoráveis do que os da Africa” (p. 395). Esses autores pressupõem que a convivência com o branco civilizado - ainda que seja como escravo - é melhor para o negro do que viver livre em culturas primitivas.

Os autores citados pelo médico baiano têm em comum a crença no processo gradual de civilização das raças - influência clara do evolucionismo social - e no constante atraso a que o negro está irremediavelmente submetido, seja por características biológicas, seja por atraso evolutivo. Não falta a eles esta ambiguidade. A influência do darwinismo social aparece em citações como esta: "O negro principalmente é inferior ao Branco, a começar da massa encephalica que pesa menos e do apparelho mastigatorio que possue caracteres animalescos, até ás faculdades de abstracção, que nelle é tão pobre e tão fraca” (Rodrigues, 1935, p. 396). A contribuição de Rodrigues a esta discussão foi afirmar que uma nação constituída por maioria negra será tanto mais atrasada quanto "mais inferior e degradado tiver sido o elemento africano introduzido pelo trafico” (p. 397). No caso brasileiro, diz ele, não vieram apenas povos africanos degradados, mas também "poucos negros dos mais adiantados e mais do que isso mestiços chamitas convertidos ao Islamismo e provenientes de estados africanos bárbaros sim, porém dos mais adiantados” (p. 398).

Foi assim que esse antropólogo e médico da Bahia fez parte do contigente de "homens de sciencia" que se valeram do que o darwinismo social e o evolucionismo tinham de mais relevante para administrar as questões sociais e políticas do primeiro período da República brasileira.

A partir daí, outros momentos políticos, outras ideologias nas ciências humanas e movimentos sociais em defesa da cidadania levaram à tendência crescente de negar a existência de preconceito racial no Brasil. Casa Grande e Senzala, de Gilberto Freyre (1933/2003), é uma obra que deu força à crença na democracia racial brasileira. Nesta direção, Schwarcz (1996) apresenta uma pesquisa sobre racismo em que $97 \%$ dos entrevistados afirmaram não ter preconceito e $98 \%$ afirmaram conhecer pessoas preconceituosas, como amigos, namorados e parentes próximos. A partir desses resultados, a autora 
conclui: "Todo brasileiro se sente como em uma ilha de democracia racial, cercado de racistas por todos os lados” (p. 155).

Apesar do discurso que nega ou ameniza a presença do preconceito e da discriminação racial no país, não é difícil ver manifestações de racismo no dia-a-dia da vida social brasileira. Ora ele é escancarado, como nos massacres freqüentes, ora é silencioso, como no olhar policial que põe constantemente os negros sob suspeita. Pesquisa recente concluiu que há diferença de tratamento, por parte da justiça, de brancos e negros. Estes são tratados com mais severidade, desde a instância policial até o tribunal, como se a criminalidade e a possibilidade de "perturbar a ordem social" lhes fosse inerente (ver Adorno, 1996).

Em 2003, o cartaz de uma campanha publicitária contra o uso de drogas dá continuidade à relação entre negritude e criminalidade: a mão que empunha a arma é negra; a que sustenta é branca. ${ }^{3}$

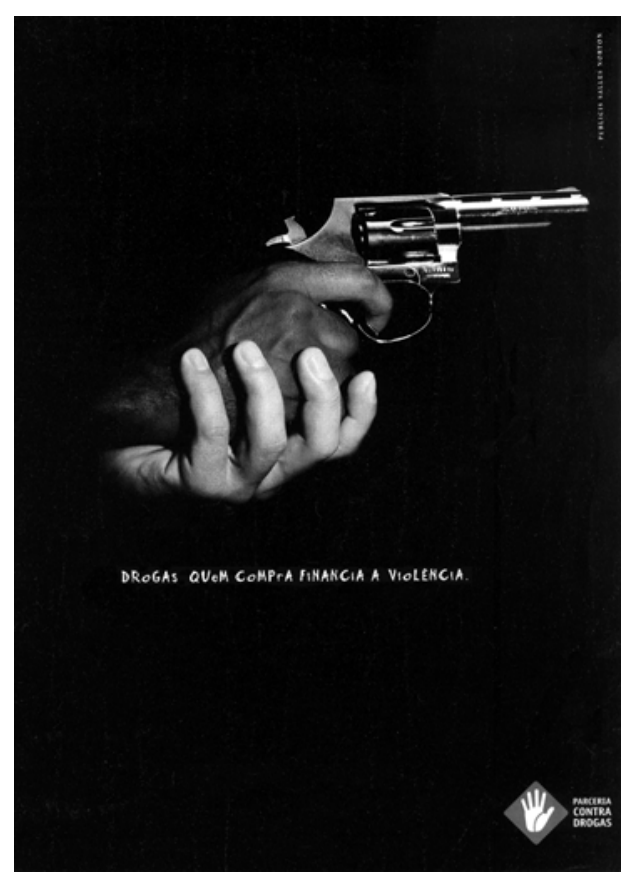

3 Isto é Gente, 14.07.2003. 
Nunes, S. S. (2006). Racism in Brazil: attempts of disguise of an explicit violence. Psicologia USP, 17 (1), 89-98.

Abstract: The black slavery in Brazil brought deep marks for the contemporary society. The present ambiguity in the post-abolition - to the black the right is not denied of being free, but it is denied conditions worthy of life, repeating a lot of times, similar logics with the slavery - of some form it persists nowadays through racists practices, explicit or not. In the present article, the origins of the Brazilian racism are analyzed through reflections about the racial relationships after the end of the slavery. The focus of the analysis is the scientific speech legitimated by the import of European racial theories in the beginning of the century XX and his appropriation for the Brazilian intellectuals, specifically, for in analysis of doctor Raimundo Nina Rodrigues' work. The justified racism for the science was the form of maintaining the treatment inequality among whites and black, on that historical moment. That inequality can still be observed in the days today. For such, the forms of expression of the current racism are discussed.

Index terms: Prejudice. Racial and ethnic relations. Social issues.

Nunes, S. S. (2006). Racisme au Brésil : tentatives de déguisement d’une violence explicite. Psicologia USP, 17 (1), 89-98.

Résumé : L’esclavage noir au Brésil a apporté profondes marques pour la société contemporain. L'ambiguïté présente dans la periode après l'abolition - au noir n'est pas nié le droit d'être libre, mais lui sont niées des conditions dignes de vie, en se répétant beaucoup de fois, logiques semblables ce de l'esclavage - de quelque forme il persiste de nos jours au moyen de pratiques racistes soient elles explicites ou non. Dans cet article, sont analysées les origines du racisme brésilien au moyen de réflexions sur les relations raciales près la fin de l'esclavage. Le centre de l'analyse est le discours scientifique légitimé par l'importation de théories raciales européennes dans le début du siècle XX et son particulière appropriation par les intellectuels brésiliens, spécifiquement, par l'analyse d'une oeuvre du médecin Raimundo Nina Rodrigues. Le racisme justifié par la science a été la forme de maintenir l'inégalité de traitement entre des blancs et des noires, au ce moment historique. Cette inégalité encore peut être observée de nos jours. Pour cela, on discute les formes d'expression du racisme actuel.

Mots-clés : Préjudice. Relations raciales et ethniques. Problèmes sociales. 


\section{Sylvia da Silveira Nunes}

\section{Referências}

Adorno, S. (1996). Violência e racismo: discriminação no acesso à justiça penal. In L. M. Schwarcz \& R. S. Queiroz (Orgs.), Raça e diversidade (pp. 255-275). São Paulo: Edusp.

Costa, A. M. (1996). A violência como marca: a pesquisa em história. In L. M. Schwarcz \& L. V. S. Reis (Orgs.), Negras imagens: ensaios sobre cultura e escravidão no Brasil (pp. 81-91). São Paulo: Edusp.

Freyre, G. (2003). Casa grande-senzala: formação da família brasileira sobre o regime da economia patriarcal (47a ed.). São Paulo: Global. (Trabalho original publicado em 1933)

Rodrigues, R. N. (1935). Os africanos no Brasil. São Paulo: Companhia Editora Nacional.

Schwarcz, L. M. (1996). As teorias raciais, uma construção histórica de finais do século XIX: o contexto brasileiro. In L. M. Schwarcz \& R. S. Queiroz (Orgs.), Raça e diversidade (pp. 147-185). São Paulo: Edusp.

Recebido em: 24.03.2006

Aceito em: 3.04.2006 